\title{
The Use of Red Rules in Patient Safety Culture
}

\author{
Lisa K. Jones ${ }^{1}$, Stephen J. O'Connor ${ }^{2, *}$ \\ ${ }^{1}$ Owensboro Medical Health System, USA \\ ${ }^{2}$ School of Health Professions, University of Alabama at Birmingham, USA
}

Copyright $\mathrm{O} 2016$ by authors, all rights reserved. Authors agree that this article remains permanently open access under the terms of the Creative Commons Attribution License 4.0 International License

\begin{abstract}
This article examines the use of Red Rules in hospital patient safety culture. The purpose of this study is to explore the effects of Red Rules on hospital staff perceptions of safety, frequency of events reported, number of events reported, and staff perceptions of non-punitive response by management. A survey was conducted among hospitals that completed the U.S. Agency for Healthcare Research and Quality Hospital Survey on Patient Safety Culture during the years 2007 to 2011. A sample of hospitals who implemented Red Rules were compared with a similar group who did not. Contrary to expectations, this study did not find statistically significant differences between the study group (Red Rules) and the comparison group (Non-Red Rules). In the absence of evidence on the use of Red Rules, some hospital leaders have elected not to use them, assuming that they are inconsistent with a just culture and with improving patient safety. The results do not provide support for this belief. Used within a commitment-based management style as a communication tool to support staff in following safety rules rather than as a disciplinary tool in a control-based environment, Red Rules can be part of a comprehensive strategy to improve patient safety.
\end{abstract}

Keywords Red Rules, Patient Safety, Safety Culture

\section{Introduction}

Since the landmark report from The Institute of Medicine (IOM), To Err is Human: Building a Safer Health System [1], the concept of patient safety has been an emerging theme in the health care literature. In spite of the widespread attention the IOM report received, progress to improve patient safety has been slow and difficult to measure [2].

Many reasons for the slow improvement of patient safety have been cited in the literature and many interventions have been attempted. Kaissi [3] posits that the patient safety movement has lagged due to an inappropriate focus on provider and patient-level factors rather than on organizational factors. A lack of attention to workforce issues such as employee competency, retention, and satisfaction is discussed as another crucial factor for improving patient safety [4]. Other initiatives have been identified including the adoption of electronic health records, the implementation of computerized physician order entry, team training, full disclosure to patients after harm events, and appointments of patient safety officers in healthcare organizations. However, the importance of culture remains a prominent and recurring theme. The patient safety follow-up report from the IOM identified the blame culture in health care as a major contributor to medical errors [5]. Five years after the first IOM report, the National Quality Forum (NQF) identified 30 safe practices for better health care. Creating a culture of safety was listed as number 1 on the list [6]. An updated report from the NQF four years later retained creating and sustaining a culture of safety as an ongoing priority [7].

In an effort to increase patient safety, healthcare organizations are not only focusing on a culture of safety, they are implementing new programs to develop and implement safe practices and to train healthcare workers in patient safety [8]. For example, an error-reduction strategy borrowed from the aviation, manufacturing, and nuclear power industries, known as Red Rules, is now being tried in hospitals. The U.S. Agency for Healthcare Research and Quality (AHRQ) defines Red Rules in the following manner: "Rules that must be followed to the letter. In the language of non-health care industries, red rules 'stop the line'. In other words, any deviation from a Red Rule will bring work to a halt until compliance is achieved. Red Rules, in addition to relating to important and risky processes, must also be simple and easy to remember" [9]. Red Rules are rules that cannot be broken. They are standards that should be used every time a specific process is used except in rare or urgent situations. If broken, they can lead to serious disciplinary action.

However, there is little evidence that Red Rules lead to safer care for patients. Further, the use of Red Rules seems to be blaming and punitive, which is in conflict with the attributes of a patient safety culture, which are characterized by trust and transparency. The concept of a culture of patient safety and the use of Red Rules seem to be inconsistent. 
The purpose of this study is to explore the effects of Red Rules on staff perceptions of safety, frequency of events reported, number of events reported, and staff perceptions of non-punitive response by hospital management. The study compares a group of U.S. general, acute care hospitals who have implemented Red Rules with a similar group that have not implemented Red Rules.

\subsection{Patient Safety Culture}

Patient safety culture is a specialized component of safety culture within the healthcare industry. The culture within hospitals plays an important role in the effectiveness of patient safety initiatives. In To Err is Human, the IOM defined patient safety as the prevention of harm to patients, where harm can occur through errors of commission and omission. It further reported that "a strong culture of safety is viewed by many in the safety field as being the most critical underlying feature of their accomplishments"[1].

Although evidence for the importance of a patient safety culture has been established, hospitals have struggled to achieve it. Barriers to achieving a culture of safety are broad in nature, ranging from technological advances to system complexity. However, most barriers are rooted in cultural traditions. While many barriers have been discussed in the literature, punishment for errors has been acknowledged as the single greatest barrier to error prevention in healthcare [10]. This action has been labeled a blaming culture.

In the past, the traditional response to medical errors in healthcare has been to identify and blame an individual when an error occurs. Frequently referred to as the "name, blame and shame" approach, those most directly involved in the event are singled out for punishment. This response leads to fear of punishment which inhibits reporting. This results in a cycle in which more errors result because the organization is not aware of errors and does not have the opportunity to learn from them. Another outcome of blaming and the fear it generates is a loss of innovation and creative problem-solving. Workers that are fearful do not take risks, which are a key component of innovation. Without innovation, problems aren't solved and errors continue [11].

Another characteristic of a blaming culture is the use of a commonly used tool in hospitals, the incident report. This form is used to track events individually. Incident reports focus on a specific event and the individuals involved rather than the circumstances and systems surrounding the event. Opportunities for learning to prevent future events are frequently lost to this reporting system [12]. Traditional incident reporting systems are routinely linked to the human resources disciplinary action function. Often, disciplinary action is taken against the individuals involved because the incident is reported as, and interpreted as, human error. Because human resource disciplinary actions are considered confidential to protect the individuals involved, an atmosphere of secrecy is created around the incident. If there is potential legal involvement, another layer of secrecy is created. This results in little opportunity for learning and prevention of similar future incidents.

An awareness of errors within an organization is key to improving patient safety. This awareness is not possible if workers are punished for unintentional mistakes. A blaming culture that punishes workers rather than improving systems incentivizes workers to hide rather than to report errors.

The IOM declared that "the biggest challenge to moving toward a safer health system is changing the culture from one of blaming individuals for errors to one in which errors are treated not as personal failures, but as opportunities to improve the system and prevent harm"[5]. With growing evidence to correct the atmosphere of a blaming culture, many hospitals moved to a blameless culture to promote reporting of errors in order to improve patient safety.

In an effort to move from a blaming culture, many hospitals strived to implement a blameless or blame free culture. The blameless culture acknowledged that a large proportion of unsafe acts were honest errors, recognized as slips, lapses and mistakes that even the best people can make. These acts were not considered to be blameworthy. It was also believed that there was little remedial or preventative benefit to punishing individuals who committed the errors. The goal of this move was to create a culture of trust and transparency where errors could be reported and reviewed without fear of punishment or shame [13]. By creating a safe environment for reporting errors, the examination and correction of errors could prevent future events.

Unfortunately, hospitals began to realize that the concept of a blameless culture had two serious weaknesses. First, it did not address instances in which individuals willfully and/or repeatedly engaged in dangerous behaviors that others would recognize as being likely to increase the risk of an adverse outcome. Second, it did not distinguish between culpable and non-culpable unsafe acts. Although the blameless culture supported workers in reporting errors, it did not include warranted punishment [14].

Given the limitations of a blameless culture and the need for hospitals to find a place between a blaming culture and a blameless culture, a middle ground is needed that includes accountability. The middle ground is a just culture.

The need for personal accountability has been identified as a necessary component of a well-rounded patient safety culture. In the literature, this emerging theme is called a "just culture" [15]. A just culture has been defined by AHRQ as a culture that "recognizes that individual practitioners should not be held accountable for system failings over which they have no control. A just culture also recognizes many individual or active errors represent predictable interactions between human operators and the systems in which they work. However, in contrast to a culture that touts 'no blame' as its governing principle, a just culture does not tolerate conscious disregard of clear risks to patients or gross misconduct (e.g., falsifying a record, performing professional duties while intoxicated). In 
summary, a just culture recognizes that competent professionals make mistakes and acknowledges that even competent professionals will develop unhealthy norms (shortcuts, "routine rule violations"), but has zero tolerance for reckless behavior" [9].

Several authors have written about the need to balance a culture of patient safety with a just culture, citing the importance of combining openness that is not punitive with personal accountability [16-23].

There are many benefits of a just culture. First, a just culture can lead to increased reporting of events and near misses, providing opportunities to prevent similar events from happening in the future. Second, a just culture builds trust throughout the organization by establishing clear boundaries for acceptable and unacceptable behavior. It also sends a message to front line workers that safety is more important than assigning blame. Third, a just culture improves operational management by establishing clear expectations for job performance and consequences for deviating from those expectations [14].

\subsection{Red Rules}

In the search for finding a balance between a blaming culture and a blameless culture, some hospitals have implemented Red Rules. Although used in other industries such as aviation and nuclear power, Red Rules are new in healthcare. Developed by E.C. Simpson, a retired executive from the nuclear industry, Red Rules are used to reduce the probability of harm to patients [24]. Red Rules should be associated with acts that have the highest level of risk to patient or employee safety if not performed exactly each and every time [25]. The most frequently cited attributes of Red Rules are: 1) They are few in number; 2) They are clear and obvious; 3) They are firm in identifying the consequences for noncompliance; and 4) They focus on decision-based rather than skill-based activities [24]. Several examples of Red Rules are found in the literature. The most commonly discussed Red Rules are: 1) Timeouts shall be performed prior to all procedures; 2) Two forms of identification shall be used to identify patients before taking action with a patient or patient information; and 3) All specimens shall be labeled at the patient's bedside.

Other examples include not only organizational but department-specific Red Rules. For example, use of standard lifts is a Red Rule in one hospital's Rehabilitation Department. In some Respiratory Departments, there is a Red Rule that ventilators shall be plugged into red emergency outlets [24].

The use of Red Rules seems to have taken a similar journey as that of patient safety culture. The early literature indicates a more punitive approach. In one example, Red Rules, if broken, result in disciplinary actions including censure and possible termination of employment [18]. In a later example, Red Rules are described as inviolate in nature with no excuses for violations accepted [26]. However, recent literature describes Red Rules as a non-punitive communication tool and a method of support for front-line staff. There is emphasis on the use of thorough communication throughout an organization when implementing Red Rules. The purpose and intent must be thoroughly explained and understood for Red Rules to have the intended results. They are used to support front line workers to stop the line when a Red Rule is being violated. Red Rules are not described as a punishment program or disciplinary process but a safety improvement tool [27].

\section{Theoretical Framework}

The Competing Values Framework [28] has been used in many studies to examine the relationship between culture and organizational effectiveness, such as patient safety [29, 30]. The framework reflects two axes: one indicates whether an organization is focused internally or externally; the other reflects dimensions between flexibility and control. Of significance to this study is the dimension of hierarchical culture which emphasizes control and formal decision-making, with enforcement of rules and regulations. This seems to be consistent with the implementation of Red Rules. Opposite the hierarchical culture is the group culture which values human relations, informal communication, and decentralized decision-making; this dimension is consistent with a patient safety culture. However, the other two dimensions of the model (Developmental and Rational) do not seem to address the variables of patient safety and Red Rules. Khatri, Brown, and Hicks [31] describe this as a limitation of the Competing Values Framework within the context of patient safety and suggest that a model comparing the characteristics of the two dimensions, Hierarchical and Group, be used instead. This model, which is based on McGregor's [32] Theory X and Theory Y management theories, was first introduced by Khatri in 2006. It proposes linkages between management philosophy and clinical outcomes by comparing control-based management outcomes with commitment-based management outcomes [33]. Control-based management assumes that people are incapable of self-discipline and can't be trusted. Therefore, they must be monitored and controlled to ensure that they behave. The consequences of this type of management include low morale, a climate of mistrust, employee turnover and absenteeism, and a sense of indifference toward work. This approach affects clinical outcomes by decreasing the detection and reporting of errors and by reducing the motivation and effort of employees. The authors describe a cycle in which errors lead to more control and monitoring of employees, which increases a blame culture, resulting in punishment, which leads to hiding of errors and lack of learning from mistakes, resulting in more errors [33].

The opposite approach, commitment-based management, assumes that people work best when they are fully committed to the organization, are trusted, and are allowed 
to work autonomously. The results are actively engaged employees who go beyond the call of duty and seek additional responsibility. A different cycle is described in which staff report errors and learn from mistakes in an open and trusting environment, resulting in a highly motivated and self-directed staff [33].

A later study tested this model and found the control-based management approach to be associated with a culture of blame. In contrast, the commitment-based approach was associated with a culture of learning from mistakes, camaraderie, and motivation [34]. The framework of control-based and commitment-based management is viewed as respectively overlaying the culture of blame and culture of safety in the most recent study by Khatri et al [31]. The model (see Figure 1) also describes the link from management approach to clinical outcomes [33].

Applying Khatri's model to the present study (see Figure 2), the management approach is represented by the implementation of Red Rules. In response to this, the human resource management practice of the disciplinary process, including suspension and termination, is enforced. From this practice, employees react with behaviors that can be counter-productive to a patient safety culture. These behaviors include hiding errors and overlooking unsafe conditions. The final step in the chain is clinical outcomes. In this scenario, clinical outcomes will worsen as a result of hidden errors and unaddressed, unsafe conditions, resulting in increased morbidity and mortality.

Using the theoretical framework for control-based and commitment-based management outcomes, it seems that Red Rules will be viewed as punitive and perceived as a form of control-based management. As a result of creating a punitive environment with the establishment of Red Rules, the frequency and number of reported errors will decrease because staff will fear the consequences of reporting errors. Finally, staff will perceive that the organization's response to errors is punitive, rather than non-punitive.

This study will examine the following hypotheses:

1. Staff perceptions of safety will diminish following the implementation of Red Rules;

2. The frequency of events reported will decrease following the implementation of Red Rules;

3. The number of events reported will decrease following the implementation of Red Rules;

4. Staff perceptions of non-punitive response will diminish following the implementation of Red Rules.

\section{Management $\longrightarrow$ HR Management $\longrightarrow$ Employee $\longrightarrow$ Clinical Approach Practices $\quad$ Behaviors Outcomes}

Note: Adapted from Figure 1: "The Model Linking Management Philosophy to Clinical Outcomes" in Naresh Khatri, Alok Baveja, Suzanne A. Boren, and Abate Mammo, in California Management Review, Vol. 48 no. 3, Spring 2006, pp. 115-141 (C) 2006 by The Regents of the University of California. Published by the University of California Press.

Figure 1. The Causal Chain from Management Approach to Clinical Outcomes.

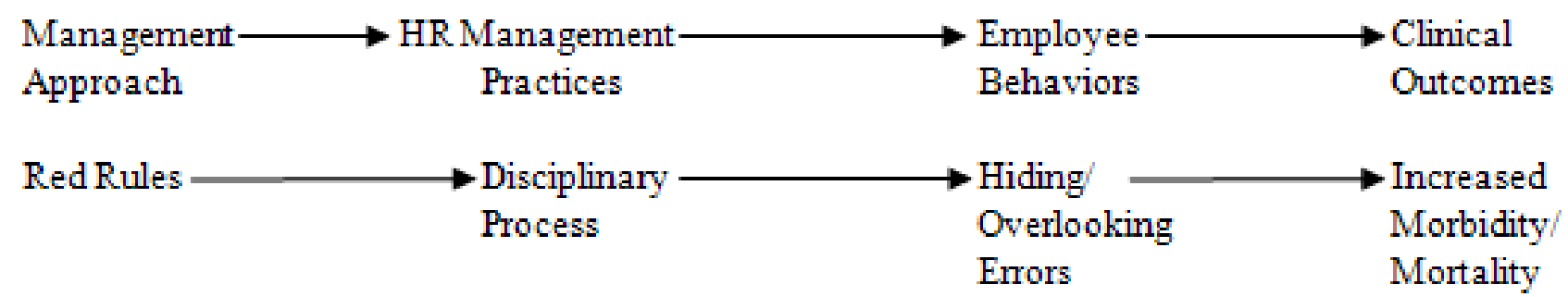

Figure 2. Example of the Causal Chain from Management Approach to Clinical Outcomes. 


\section{Methods}

\subsection{Study Design and Data Sources}

This study compared four measures of patient safety culture among two groups of hospitals that completed the AHRQ Hospital Survey on Patient Safety Culture. The two groups consisted of a study group of hospitals that have implemented Red Rules as a patient safety strategy; the comparison group was comprised of hospitals that have not implemented Red Rules. The four measures used from the AHRQ survey were: 1) Staff perceptions of safety; 2) Frequency of events reported; 3) Number of events reported; and 4) Staff perceptions of no punitive response.

\subsection{Validity and Reliability of the AHRQ Survey}

The AHRQ survey is sponsored by the Quality Interagency Coordination Task Force and is funded by AHRQ. The assessment tool includes 42 items reflecting 12 dimensions of patient safety culture and has demonstrated acceptable psychometric properties [35].

\subsection{Selection of Hospitals}

This study was designed for hospitals that completed the AHRQ Hospital Survey on Patient Safety Culture within the five year period (2007 through 2011). The study group consisted of hospitals that have implemented Red Rules as a patient safety strategy and a comparison group consisting of hospitals that have not implemented Red Rules. Since hospitals that have implemented Red Rules are limited and difficult to identify, hospitals involved in structured patient safety initiatives likely to use strategies such as Red Rules were targeted for participation. Invitations were distributed via e-mail with a link to the web-based Red Rules survey to the VHA Central Target Zero Patient Safety Collaborative, Kentucky Hospital Association (KHA) Accreditation, and Institute for Healthcare Improvement (IHI) Patient Safety Executive listserves. These groups were initially selected for inclusion due to their high level of patient safety initiatives and their willingness to distribute the survey. The e-mails were addressed to individuals responsible for patient safety activities within acute, general care hospitals involved with patient safety initiatives.

To increase the number of hospitals in the sample, snowball sampling was also conducted among colleagues working in hospitals that are using Red Rules. They were asked to identify other hospitals that use Red Rules for potential participation in the study.

A reminder e-mail was sent two weeks after the original invitation was distributed. In addition, participants were offered a token of appreciation (a 4 GB USB flash drive) and a chance to win a Visa gift card for completing the survey.

\subsection{Data Collection}

From the responses received, hospitals were grouped into those that had implemented Red Rules and those that did not. Within the group of hospitals that had implemented Red Rules, AHRQ survey results obtained six months to two years after implementing Red Rules were used. Hospitals that implemented Red Rules less than six months or longer than two years, after completing the AHRQ survey were not included in the study.

\subsection{Measures and Variables}

The independent variable is a dichotomous measure identifying whether Red Rules were used, or not used, by a hospital. This was obtained through the web-based survey.

The four dependent variables in this study were each measured by item statements from the AHRQ Hospital Survey on Patient Safety Culture. The first is: "Staff perceptions of safety." Participants were asked to respond to four statements using a 5-point Likert scale ranging from Strongly Disagree (1) to Strongly Agree (5). This variable is calculated by averaging the percentage of positive responses (Agree, Strongly agree) to each statement comprising the composite: 1) Patient safety is never sacrificed to get more work done; 2) Our procedures and systems are good at preventing errors from happening; 3) It is just by chance that more serious mistakes don't happen around here (reverse worded); and 4) We have patient safety problems in this unit (reverse worded).

The second dependent variable is: "Frequency of events reported." Respondents were asked to respond to these items using a 5-point Likert scale ranging from Never (1) to Always (5). A composite score was calculated by averaging the percentage of positive responses (Most of the time, Always) to the three questions comprising this variable: 1 ) When a mistake is made, but is caught and corrected again before affecting the patient, how often is this reported? 2) When a mistake is made, but has no potential to harm the patient, how often is this reported? 3) When a mistake is made that could harm the patient, but does not, how often is this reported?

The third dependent variable is "Number of events reported." Respondents were asked to indicate the number of events they have reported over the past 12 months. Response choices included 1) No events; 2) 1 to 2 events; 3) 3 to 5 events; 4) 6 to 10 events; 5) 11 to 20 events; and 6) 21 events or more. As some respondents answered as a percentage and others as raw numbers, the variable was adjusted to reflect percentage of two responses: 1) No events or 2) One or more events. The percentages of the two responses, No events (56\%) and one or more events (44\%), equaled $100 \%$ for each hospital after the conversion was completed.

The third dependent variable is "Staff perceptions of no punitive response." All three item statements are reverse worded and use responses on a 5-point Likert scale from Strongly Disagree (1) to Strongly Agree (5). A composite score is derived by averaging the percentage of positive responses (Strongly disagree, Disagree) to the following 
three statements: 1) Staff feel like their mistakes are held against them; 2) When an event is reported, it feels like the person is being written up not the problem; 3) Staff worry that mistakes they make are kept in their personnel file.

Characteristics of the participating hospitals in both groups were examined for significant differences in terms of: 1) bed size, 2) teaching status, 3) ownership and control, and 4) geographic region.

\section{Results}

There were 478 visits to the survey, with 213 surveys either partially or totally completed. Of the 213 surveys, $149(70 \%)$ were partially completed and $64(30 \%)$ were totally completed. The incomplete surveys lacked responses to the four dependent variable questions from the AHRQ survey. This was due to the fact that those hospitals did not take the AHRQ survey, and thus were unable to answer those questions. Descriptive statistics for completed and partially completed surveys are presented in Table 1 . Overall, the majority of hospitals were non-teaching (67.6\%) and nongovernment (89.1\%).

Descriptive statistics for the completed surveys are presented in Table 2. Of the 64 completed surveys, twenty-nine hospitals were in the study group (Red Rules) and thirty-five hospitals were in the comparison group (Non-Red Rules).

The total number of individual respondents taking the AHRQ survey within those 64 hospitals was 66,095 . The AHRQ Hospital Survey on Patient Safety Culture 2012 User Comparative Database Report reports that $90 \%$ of hospitals administer the survey to all staff. Otherwise, it is administered to a sample of staff in all departments within the hospital [38]. The majority (76\%) of respondents reported that they had direct interaction with patients, with thirty-five percent in a nursing role. AHRQ reports that the characteristics of the hospitals in the database are consistent with those of hospitals in the American Hospital Association [38]. Similar characteristics were found in this study.

Due to variation in completed and partially completed surveys, a chi-square test was first conducted to assess differences in respondents completing the survey and those not completing the survey by the four hospital characteristics (bed size, teaching status, ownership and control, geographic region). The results were not significant, indicating that these particular variables did not explain the completion, or lack of completion, of the surveys.

To ascertain differences in hospital characteristics (bed size, teaching status, ownership and control, geographic region) between hospitals that use Red Rules and those that do not, a chi-square test was conducted (Table 2). Of the four characteristics, only ownership and control had a $\mathrm{p}$-value approaching significance, $\chi^{2}(1, \mathrm{~N}=64)=4.494, \mathrm{p}=$ 0.06 . To rule out any masking effects of ownership and control, a linear regression was conducted for each of the four outcome variables (staff perceptions of safety, frequency of events reported, percentage of events reported, and staff perceptions of non-punitive response) using ownership and control as a covariate. These analyses ruled out ownership and control as a masking variable for all primary outcomes variables.

Independent samples t-tests were conducted on the outcome variables to determine differences between hospitals that use Red Rules and those that do not use Red Rules. No statistically significant differences in the four outcome variables were observed (Table 3).

Table 1. Descriptive Statistics for Completed and Partially Completed surveys

\begin{tabular}{|c|c|c|c|c|}
\hline Characteristic & Overall responses & Partial responses & Complete responses & $p$ value \\
\hline Bed size & $213(100.0)$ & $149(70.0)$ & $64(30.0)$ & 0.10 \\
\hline 6-99 & $60(28.2)$ & $43(28.9)$ & 17 (26.6) & \\
\hline $100-299$ & $67(31.5)$ & $51(34.2)$ & $16(25.0)$ & \\
\hline $300-499$ & $50(23.5)$ & $28(18.8)$ & $22(34.4)$ & \\
\hline $500+$ & $36(16.9)$ & $27(18.1)$ & $9(14.1)$ & \\
\hline Teaching status & $213(100.0)$ & $149(70.0)$ & $64(30.0)$ & 0.17 \\
\hline Teaching & $69(32.4)$ & $44(29.5)$ & $25(39.1)$ & \\
\hline Non-teaching & $144(67.6)$ & $105(70.5)$ & $39(60.9)$ & \\
\hline Ownership and control & *202 (100.0) & $138(68.3)$ & $64(31.7)$ & 0.34 \\
\hline Government & $22(10.9)$ & $17(12.3)$ & $5(7.8)$ & \\
\hline Nongovernment & $180(89.1)$ & $180(89.1)$ & $59(92.2)$ & \\
\hline Geographic region & $* 202(100.0)$ & $138(68.3)$ & $64(31.7)$ & 0.17 \\
\hline Mid \& South Atl./ New England & $92(45.5)$ & $59(42.8)$ & $33(51.6)$ & \\
\hline East North \& South Central & $55(27.2)$ & $35(25.4)$ & $20(31.3)$ & \\
\hline West North \& South Central & $24(11.9)$ & $20(14.5)$ & $4(6.3)$ & \\
\hline Mountain/Pacific/Assoc. Territories & $31(15.3)$ & $24(17.4)$ & $7(10.9)$ & \\
\hline
\end{tabular}

*Eleven respondents did not answer. 
Table 2. Descriptive Statistics for Completed Surveys

\begin{tabular}{|c|c|c|c|c|}
\hline Characteristic & $\begin{array}{c}\text { Overall } \\
(\mathrm{n}=64, \%=100)\end{array}$ & $\begin{array}{c}\text { Red Rules } \\
(\mathrm{n}=29, \%=45)\end{array}$ & $\begin{array}{l}\text { Non-Red Rules } \\
(\mathrm{n}=35, \%=55)\end{array}$ & $p$ value \\
\hline Bed size & & & & 0.36 \\
\hline $6-99$ & $17(26.6)$ & $10(15.6)$ & $7(10.9)$ & \\
\hline $100-299$ & $16(25.0)$ & $5(7.8)$ & $11(17.2)$ & \\
\hline $300-499$ & $22(34.4)$ & $11(17.2)$ & $11(17.2)$ & \\
\hline $500+$ & $9(14.1)$ & $3(4.7)$ & $6(9.4)$ & \\
\hline Teaching status & & & & $>0.99$ \\
\hline Teaching & $25(39.1)$ & $18(28.1)$ & $21(32.8)$ & \\
\hline Non-teaching & $39(60.9)$ & $11(17.2)$ & $14(21.9)$ & \\
\hline Ownership and control & & & & 0.06 \\
\hline Government & $5(7.8)$ & $0(0)$ & $5(7.8)$ & \\
\hline Nongovernment & $59(92.2)$ & $29(45.3)$ & $30(46.9)$ & \\
\hline Geographic region & & & & 0.84 \\
\hline Mid \& South Atl./ New England & $33(51.6)$ & $15(23.4)$ & $18(28.1)$ & \\
\hline East North \& South Central & $20(31.3)$ & $10(15.6)$ & $10(15.6)$ & \\
\hline West North \& South Central & $4(6.3)$ & $1(1.6)$ & $3(4.7)$ & \\
\hline Mountain/Pacific/Assoc. Territories & $7(10.9)$ & $3(4.7)$ & $4(6.3)$ & \\
\hline
\end{tabular}

Table 3. Independent Samples t-test for Completed Surveys

\begin{tabular}{|c|c|c|c|c|}
\hline Outcomes & $\begin{array}{c}\text { Overall } \\
\text { Mean }\end{array}$ & $\begin{array}{c}\text { Red Rules } \\
\text { Mean }\end{array}$ & $\begin{array}{c}\text { Non-Red Rules } \\
\text { Mean }\end{array}$ & $p$ value \\
\hline Staff perceptions of safety $(\mathrm{n}=64)$ & $65.9 \pm 12.4$ & $64.8 \pm 10.3$ & $66.8 \pm 13.0$ & 0.53 \\
\hline Frequency of events reported $(\mathrm{n}=64)$ & $63.1 \pm 14.6$ & $63.2 \pm 16.3$ & $62.9 \pm 13.3$ & 0.93 \\
\hline Percentage of events reported ( $\mathrm{n}=59)$ & & & & \\
\hline No events & $52.5 \pm 14.6$ & $54.8 \pm 15.3$ & $50.5 \pm 14.0$ & 0.27 \\
\hline 1 or more events & $47.5 \pm 14.6$ & $45.2 \pm 15.3$ & $49.5 \pm 14.0$ & 0.27 \\
\hline Staff perceptions of non-punitive & & & & \\
\hline response ( $\mathrm{n}=64)$ & $44.8 \pm 13.4$ & $44.7 \pm 12.6$ & $44.9 \pm 14.3$ & 0.96 \\
\hline
\end{tabular}

The purpose of this study was to explore the effects of Red Rules on staff perceptions of safety, frequency of events reported, number of events reported, and staff perceptions of non-punitive response by hospital management. The theoretical framework for control-based and commitment-based management outcomes was used to frame four hypotheses.

Hypothesis \#1: Staff perceptions of safety will diminish following the implementation of Red Rules

The overall mean for staff perceptions of safety was 65.9 out of a possible 100, suggesting room for improving this outcome. Although the independent samples t-test did not show statistical significance between the study group and the comparison group $(p=0.53)$, the mean for hospitals using Red Rules was lower at 64.8 , compared with 66.8 in hospitals that do not use Red Rules. This finding suggests the potential for decreased perceptions of safety among the study group (Red Rules), depending on the presence of other conditions discussed in the literature, such as a blaming culture rather than a just culture.
Hypothesis \#2: The frequency of events reported will decrease following the implementation of Red Rules

The frequency of events reported had an overall mean of 63.1, with Red Rules hospitals having a slightly higher mean of 63.2 than hospitals that do not use Red Rules at 62.9. The comparison did not show significance $(\mathrm{p}=0.93)$.

This outcome may reflect the effect of hospital campaigns to increase staff reporting of errors used in conjunction with the implementation of Red Rules. One hospital in the Midwest has communicated the importance of transparency and open communication to support the development of a just culture. Although the organization uses Red Rules, which can result in disciplinary action, including dismissal, the structure supports the concept of good citizenship to improve patient safety [18].

A recent study on error disclosure found that staff who receive error disclosure training reported significantly higher levels of error disclosure culture and error disclosure trust culture. This study points to the positive impact of staff training in reporting errors to allow organizations to understand needed improvements resulting in fewer medical 
errors [36]. It is likely that hospitals that have implemented Red Rules and other patient safety strategies have conducted staff training on event reporting, resulting in no significant difference in the hospital groups in this study.

Hypothesis \#3: The number of events reported will decrease following the implementation of Red Rules

The percentage of events reported was assessed using two variables: 1) no events reported or 2) one or more events reported. The mean for no events was $52.5 \%$; the mean for one or more events was $47.5 \%$. This suggests that although staff responded that they identify and report errors, when asked the number of events actually reported, most did not report any events. Respondents from hospitals using Red Rules had the higher mean for reporting no events at $54.8 \%$; the mean was $50.5 \%$ in non-Red Rules hospitals. However, this was not a significant finding $(p=$ 0.27). Conversely, when reporting one or more events, respondents in non-Red Rules hospitals had a higher mean of $49.5 \%$ compared with a mean of $45.2 \%$ in Red Rules hospitals.

The low mean scores for frequency of events reported and percentage of events reported in this study are consistent with a recent report from the Office of Inspector General [37]. The report found that in 189 hospitals surveyed, hospital staff did not report $86 \%$ of events experienced by Medicare beneficiaries. Hospital administrators attributed the lack of reporting to staff misperceptions about what constitutes harm and what constitutes a reportable event. However, among the reasons given for events not being reported, fear of a punitive response was not listed. It is unclear from the report whether hospital administrators were provided a list of reasons to choose from or whether their responses were provided through an open-ended response format. In either case, fear of no punitive response is not represented as a reason given for not reporting patient safety events.

\section{Hypothesis \#4: Staff perceptions of non-punitive response will diminish following the implementation of Red Rules}

Staff perceptions of non-punitive response had a low overall mean of 44.8 out of 100 with almost no difference between the two groups $(p=0.96)$. This variable had the lowest mean score of the four outcome variables. This finding is consistent with AHRQ data reporting 44\% positive response among 567,703 hospital staff respondents from 1,128 hospitals [38]. Non-punitive response to error has shown little improvement since the first AHRQ Patient Safety Culture report in 2007 [39]. Approximately 20\% of hospitals have improved their scores in this category over the past 5 years, while $16 \%$ have experienced lower scores.

\subsection{Assessment of Findings}

Contrary to expectations, this study did not find a significant difference between the study group (Red Rules) and the comparison group (Non-Red Rules). One possible explanation for this lies in the level of awareness and effort in improving patient safety among the hospitals that participated in the study. In order to participate, hospitals were required to have completed the AHRQ Hospital Survey on Patient Safety Culture. This activity can be an indicator of a higher level of awareness and interventions regarding patient safety. Hospitals that have assessed their patient safety culture possibly possess a higher "mindfulness" for patient safety, resulting in strategies to reduce errors, and are advancing toward being a high reliability organization. A single tool such as Red Rules would more than likely not have an effect on patient safety culture, if used with other initiatives within a just culture.

Another explanation could lie in the timing of the implementation of Red Rules among the study group. As noted previously, hospitals are evolving from a blaming culture to a just culture environment. The literature on Red Rules has also evolved from a tool associated with the disciplinary process to a tool used to support communication on critical safety issues. Within the study group of hospitals using Red Rules, the implementation year with the largest number of hospitals was 2007 with 11 $(37.9 \%)$ hospitals. This could indicate that in the absence of evidence-based effectiveness, hospitals have hesitated to implement Red Rules. Those that have implemented Red Rules in more recent years are likely to have used a more commitment-based approach than a control-based approach, using Red Rules as a communication tool rather than a disciplinary tool.

\section{Practice Implications}

In the absence of evidence on the use of Red Rules, some hospital leaders have elected not to use them, assuming that they are inconsistent with a just culture and with improving patient safety. This study does not provide support for this belief. Used within a commitment-based management style as a communication tool to support staff in following safety rules rather than as a disciplinary tool in a control-based environment, Red Rules can be part of a comprehensive strategy to improve patient safety. An example would be a Red Rule that is established to ensure the marking of a surgical site with a patient before anesthesia is administered and again by the operating team prior to incision. This process is considered effective in preventing wrong-site surgery. In a control-based management approach, failure to complete site marking would result in an automatic serious disciplinary action, which would cause other staff to hide similar incidents, which could lead to wrong-site surgery. In a commitment-based management approach, the principles of a "just culture" would be used to determine if the failure to mark the site was an honest mistake due to a system process or barrier, training deficiency, or other causes. The organization would use information from this error to correct processes in order to prevent similar lapses in the future. 
To be consistent with a commitment-based management style, management might consider changing the name of Red Rules, which sounds controlling and threatening, to a name reflecting a commitment-based approach, such as "Safety Stops". The name of a tool can be an indication to staff of empowerment and support or discipline and blame. Red Rules are one of many tools that can be utilized to improve patient safety, which is the ultimate goal.

\subsection{Summary}

Patient safety is a critical component of healthcare management. Effective strategies to reduce medical errors and improve patient safety are of great importance to both givers and receivers of healthcare. Without evidence, healthcare managers are unable to make informed decisions about effective strategies to reduce harm. As resources become more limited, implementation of evidence-based strategies becomes more important.

This study sought to determine the effect of Red Rules on patient safety culture and is the first quantitative study on the use of Red Rules. The research did not show significant differences between hospitals that use Red Rules and those that do not. More studies quantifying the effectiveness of strategies are needed to make the best use of the dwindling resources in healthcare. This study serves as a practical tool to inform healthcare managers of the use of one emerging strategy in the fight for patient safety.

\section{REFERENCES}

[1] Kohn, L., Corrigan, J., \& Donaldson, M. (1999). To err is human: Building a safer health system. Washington, D.C.: National Academy Press.

[2] Leape, L., \& Berwick, D. (2005). Five years after to err is human: What have we learned? Journal of the American Medical Association, 293(19), 238490.

[3] Kaissi, A. (2006). An organizational approach to understanding patient safety and medical errors. The Health Care Manager, 25(4), 292-305.

[4] Gelinas, L., \& Loh, D. (2004). The effect of workforce issues on patient safety. Nursing Economics, 22(5), 266-279.

[5] Institute of Medicine (2001). Crossing the quality chasm: A new system for the 21 st century. Washington, DC: National Academies Press.

[6] Agency for Healthcare Research and Quality. (2005). 30 safe practices for better health care: Fact sheet. Retrieved October 15, 2011, 2011 from http://www.ahrq.gov/qual/30safe.pdf

[7] National Quality Forum. (2009). Safe practices for better healthcare-2009 update: A consensus report Retrieved October 14, 2011, 2011, from http://www.qualityforum.org/ Publications/2009/03/Safe_Practices_for_Better_Healthcare \%e2\%80\%932009_Update.aspx.
[8] Leape, L., Berwick, D., Clancy, C., Conway, J., Gluck, P., Guest, J. (2009). Transforming healthcare: a safety imperative. Quality and Safety in Health Care, 18, 424-428.

[9] Patient safety network glossary. (2011). Agency for Healthcare Research and Quality Retrieved October 14, 2011, from http://www.psnet.ahrq.gov/glossary.aspx?indexLetter= R.

[10] Leape, L. Testimony to United States Congress House Committee on Veterans' Affairs. Washington, DC. (October 12, 1997)

[11] Paul, M. (1997). Moving from blame to accountability. The Systems Thinker, 8(1), 1-4.

[12] Morath, J., \& Leary, M. (2004). Creating safe spaces in organizations to talk about safety. Nursing Economics, 22(6), 344-354.

[13] Pizzi, L., Goldfarb, N., \& Nash, D. (2001). Promoting a culture of safety. In: Shojania, K., Duncan, B., McDonald K., Wachter, R., eds. Making Health Care Safer: A Critical Analysis of Patient Safety Practices. Evidence Report/Technology Assessment (Vol. 43): Agency for Healthcare Research and Quality: AHRQ Publication No. 01-E058. Retrieved from http://www.ncbi.nlm.nih.gov/book s/bv.fcgi?rid=hstat1.section. 61719

[14] GAIN Working Group E. (2004). Flight Ops/ATC Ops Safety Information Sharing. A roadmap to a just culture: Enhancing the safety environment. (1st ed.). Retrieved from http://204.108.6.79/products/documents/roadmap $\% 20$ to $\% 20$ a\%20just $\% 20$ culture.pdf.

[15] Marx, D. (2001). Patient safety and the "just culture": A primer for health care executives. New York, NY: Columbia University.

[16] Conner, M., Duncombe, D., Barclay, E., Bartel, S., Bordon, C., \& Gross, E. (2007). Creating a fair and just culture: One institution's path toward organizational change. The Joint Commission Journal on Quality and Patient Safety, 33(10), 617-624.

[17] Conway, J., Federico, F., Stewart, K., \& Campbell, M. (2010). Respectful management of serious clinical adverse events. IHI Innovation Series white paper. Cambridge, MA: Institute for Healthcare Improvement.

[18] Frankel, A., Leonard, M., \& Denham, C. (2006). Fair and just culture, team behavior, and leadership engagement: The tools to achieve high reliability. Health Services Research, 41(4p2), 1690-1709.

[19] Gorzeman, J. (2008). Balancing just culture with regulatory standards. Nursing Administration Quarterly, 32(4), 308-311.

[20] Leape, L., \& Fromson, J. (2006). Problem doctors: Is there a system-level solution? Annals of Internal Medicine, 144(2), 107-115.

[21] Reason, J. (1997). Managing the risks of organizational accidents. Hampshire, United Kingdom: Ashgate.

[22] Wachter, R., \& Pronovost, P. (2009). Balancing "no blame" with accountability in patient safety. New England Journal of Medicine, 361(14), 1401-1406. doi: 10.1056/NEJMsb090 3885 . 
[23] Walton, M. (2004). Creating a "no blame" culture: have we got the balance right? Quality Safety Health Care, 13(3), 163-164. doi: 10.1136/qshc.2004.010959.

[24] Bisognano, M., Lloyd, R., \& Schummers, D. (2007). 10 powerful ideas for improving patient care: Book 3. Chicago, IL: Health Administration Press.

[25] Clapper, C. (2011). Learning about red rules \& planning for implementation [PowerPoint slides]: Healthcare Performance Improvement, LLC.

[26] Strong red rules and safety cells cut errors. (2011). Healthcare Risk Management, HighBeam Research. Retrieved from http://www.highbeam.com.

[27] Grissinger, M. (2012). Some red rules shouldn't rule in hospitals. Pharmacy \& Therapeutics, 37(1), 4-5.

[28] Quinn, R., \& Rohrbaugh, J. (1983). A spatial model of effectiveness criteria: Towards a competing values approach to organizational analysis. Management Science, 29(3), 363-377.

[29] Davies, H., Mannion, R., Jacobs, R., Powell, A., \& Marshall, M. (2007). Exploring the relationship between senior management team culture and hospital performance. Medical Care Research and Review, 64(1), 46-65. doi: $10.1177 / 1077558706296240$

[30] Singer, S., Falwell, A., Gaba, D., Meterko, M., Rosen, A., Hartmann, C. (2009). Identifying organizational cultures that promote patient safety. Health Care Management Review, 34(4), 300-311.

[31] Khatri, N., Brown, G., \& Hicks, L. (2009). From a blame culture to a just culture in health care. Health Care Management Review, 34(4), 312-322.

[32] McGregor, D. (1985). The human side of enterprise. New York: McGraw-Hill.
[33] Khatri, N., Baveja, A., Boren, S., \& Mammo, A. (2006). Medical errors and quality of care: From control to commitment. California Management Review, 48(3), 115-141.

[34] Khatri, N., Halbesleben, J., Petroski, G., \& Meyer, W. (2007). Relationship between management philosophy and clinical outcomes. Health Care Management Review, 32(2), 128-139.

[35] Sorra, J., \& Nieva, V. (2004). Pilot study for the hospital survey on patient safety culture: A summary of reliability and validity findings. In AHRQ (Ed.), Hospital Survey on Patient Safety Culture. Rockville, MD: U.S. Department of Health and Human Services.

[36] Etchegaray, J., Gallagher, T., Bell, S., Dunlap, B., \& Thomas, E. (2012). Error disclosure: a new domain for safety culture assessment. British Medical Journal Quality \& Safety. doi: 10.1136/bmjqs-2011-000530.

[37] Levinson, D. (2012). Hospital incident reporting systems do not capture most patient harm (Report No. OEI-06-09-00091). U.S. Department of Health and Human Services. Washington, DC: Office of Inspector General.

[38] Sorra, J., Famolaro, T., Dyer, N., Nelson, D., Smith, S. Hospital Survey on Patient Safety Culture: 2012 User Comparative Database Report. Prepared by Westat, Rockville, MD, under Contract No. HHSA 290200710024C. AHRQ Publication No. 12-0017, January 2012. Agency for Healthcare Research and Quality, Rockville, MD. Retrieved from http://www.ahrq.gov/qual/hospsurvey12/index.html.

[39] American Medical Association. (2012). Fear of punitive response to hospital errors lingers. American Medical News Retrieved February 21, 2012, from http://www.ama-assn.org/amednews/2012/02/20/prl20220.ht $\mathrm{m}$. 